\title{
Life cycle strain monitoring in glass fibre reinforced polymer laminates using embedded fibre Bragg grating sensors from manufacturing to failure
}

Nielsen, Michael Wenani; Schmidt, Jacob Wittrup; Høgh, Jacob Herold; Waldbjørn, Jacob Paamand; Hattel, Jesper Henri; Løgstrup Andersen, Tom; Markussen, Christen Malte

Published in:

Journal of Composite Materials

Link to article, DOI:

$10.1177 / 0021998312472221$

Publication date:

2013

Document Version

Publisher's PDF, also known as Version of record

Link back to DTU Orbit

Citation (APA):

Nielsen, M. W., Schmidt, J. W., Høgh, J. H., Waldbjørn, J. P., Hattel, J. H., Løgstrup Andersen, T., \& Markussen, C. M. (2013). Life cycle strain monitoring in glass fibre reinforced polymer laminates using embedded fibre Bragg grating sensors from manufacturing to failure. Journal of Composite Materials, 48(3), 365-381. https://doi.org/10.1177/0021998312472221

\section{General rights}

Copyright and moral rights for the publications made accessible in the public portal are retained by the authors and/or other copyright owners and it is a condition of accessing publications that users recognise and abide by the legal requirements associated with these rights.

- Users may download and print one copy of any publication from the public portal for the purpose of private study or research.

- You may not further distribute the material or use it for any profit-making activity or commercial gain

- You may freely distribute the URL identifying the publication in the public portal 


\section{Journal of Composite Materials}

http://jcm.sadgepub.com/

\section{Life cycle strain monitoring in glass fibre reinforced polymer laminates using embedded fibre Bragg} grating sensors from manufacturing to failure

Michael W Nielsen, Jacob W Schmidt, Jacob H Høgh, Jacob P Waldbjørn, Jesper H Hattel, Tom L Andersen and Christen M Markussen

Journal of Composite Materials published online 15 January 2013

DOI: $10.1177 / 0021998312472221$

The online version of this article can be found at:

http://jcm.sagepub.com/content/early/2013/01/14/0021998312472221

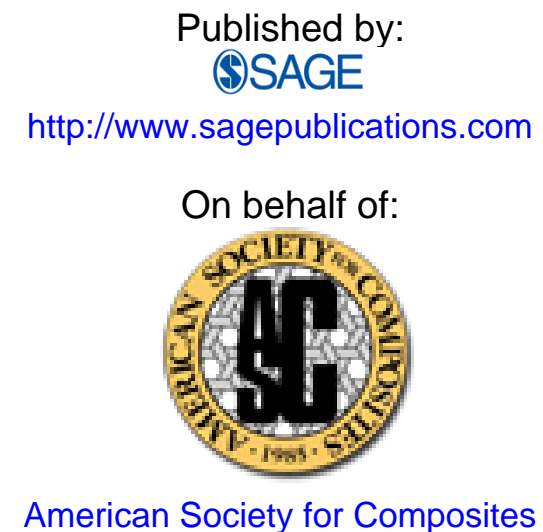

Additional services and information for Journal of Composite Materials can be found at:

Email Alerts: http://jcm.sagepub.com/cgi/alerts

Subscriptions: http://jcm.sagepub.com/subscriptions

Reprints: http://www.sagepub.com/journalsReprints.nav

Permissions: http://www.sagepub.com/journalsPermissions.nav

>> OnlineFirst Version of Record - Jan 15, 2013

What is This? 


\title{
Life cycle strain monitoring in glass fibre reinforced polymer laminates using embedded fibre Bragg grating sensors from manufacturing to failure
}

Journal of Composite Materials 0 (0) $1-17$

\author{
Michael W Nielsen', Jacob W Schmidt ${ }^{2}$, Jacob H Høgh ${ }^{3}$, \\ Jacob P Waldbjørn ${ }^{2}$, Jesper $\mathbf{H}$ Hattel ', Tom $L$ Andersen $^{3}$ and \\ Christen M Markussen ${ }^{3}$
}

\begin{abstract}
A holistic approach to strain monitoring in fibre-reinforced polymer composites is presented using embedded fibre Bragg grating sensors. Internal strains are monitored in unidirectional E-glass/epoxy laminate beams during vacuum infusion, curing, post-curing and subsequent loading in flexure until failure. The internal process-induced strain development is investigated through use of different cure schedules and tool/part interactions. The fibre Bragg grating sensors successfully monitor resin flow front progression during infusion, and strain development during curing, representative of the different cure temperatures and tool/part interfaces used. Substantial internal process-induced strains develop in the transverse fibre direction, which should be taken into consideration when designing fibre-reinforced polymer laminates. Flexure tests indicate no significant difference in the mechanical properties of the differently cured specimens, despite the large differences in measured residual strains. This indicates that conventional flexure testing may not reveal residual strain or stress effects at small specimen scale levels. The internal stresses are seen to influence the accuracy of the fibre Bragg gratings within the loading regime. This study confirms the effectiveness of composite life cycle strain monitoring for developing consistent manufacturing processes.
\end{abstract}

\section{Keywords}

Strain monitoring, fibre Bragg grating sensors, curing, process-induced strains, life cycle, composite

\section{Introduction}

Fibre-reinforced polymer (FRP) composites are widely used in various industrial applications. Such materials provide low weight, excellent corrosion resistance and high strength, which are beneficial properties in, for instance, the construction of commercial wind turbine blades and civil structures. The manufacturing process of the composite structure can, however, greatly influence the performance of the part, which is dependent on the presence of voids, dry spots, matrix cracks, waviness of the ply stack and other manufacturing-related defects. Such defects can result in crack initiation when the structure is loaded and premature failure at lower loads than expected when designing the structure.

During the manufacture of thermosetting matrix composites, a material state transition of the resin occurs, from a viscous, to rubbery and glassy state during curing. It is within this transition that various mechanisms result in the development of processinduced stresses in the composite structure, which when unconstrained result in shape distortions. ${ }^{1-3}$

\footnotetext{
'Department of Mechanical Engineering, Technical University of Denmark, Denmark

${ }^{2}$ Department of Civil Engineering, Technical University of Denmark, Denmark

${ }^{3}$ Department of Wind Energy, Technical University of Denmark, Denmark
}

\section{Corresponding author:}

Michael W Nielsen, Department of Mechanical Engineering, Technical University of Denmark, Produktionstorvet, Bygning 425, 2800 Kongens Lyngby, Denmark.

Email: mwni@mek.dtu.dk 
In cases where these process-induced stresses are sufficiently large and unavoidable, for instance due to strong internal or external constraints, they can result in various strength reducing mechanisms that support premature failure. For instance, large process-induced residual stresses are known to induce matrix cracking, interfacial debonding and delamination in fibre-reinforced composites. ${ }^{1}$ In other works, ${ }^{4-6}$ demonstrated that for thick-walled composite tubes, residual stresses can be so great that matrix cracking was promoted. At a micromechanic level, Nedele and Wisnom ${ }^{7}$ showed that process-induced stresses at the fibre-matrix interface can be as large as $30 \mathrm{MPa}$, due to the combination of hoop and radial stress components. This stress magnitude is substantial considering that the typical tensile strength of epoxy matrix materials is approximately 60 $65 \mathrm{MPa}$. Furthermore, due to the viscoelastic nature of the polymer matrix material, large process-induced residual stresses can also influence the long-term dimensional stability of the part, due to creep or stress relaxation behaviour.

The main mechanisms responsible for processinduced shape distortions and residual stresses are: (a) the thermal expansion mismatch of the constituent materials; (b) matrix chemical shrinkage during curing; and (c) interactions at the tool/part interface..$^{2,3,8-11}$ Of particular interest, when considering thick laminate composites is also the manufacturing cure cycle design. High cure temperatures and fast heating/cooling rates can result in highly non-uniform temperature and cure gradients within the part resulting in differential curing and subsequent development of internal stresses. ${ }^{3,46,11}$ Similar effects in the form of a non-uniform distribution of in-plane shear stresses can arise due to constraints posed by tooling during processing. ${ }^{10,12}$ A combination of the above-named residual stress mechanisms and manufacturing defects can cause local premature failure at lower load magnitudes than would otherwise be predicted in a defect-free composite structure.

In order to experimentally monitor the internal strain development during manufacturing, the use of fibre optic sensors has gained approval as a desirable in situ method. ${ }^{13-24}$ Apparent advantages include their ease of integration structurally during the composite manufacturing phase and the minimal influence to the host part structural properties. In recent works by the authors, fibre Bragg grating (FBG) sensors were successfully embedded in a laminate composite for cure strain monitoring purposes. ${ }^{19}$ As opposed to the use of conventional non-intrusive strain/deformation monitoring methods (e.g. using strain gauges (SGs) or digital image correlation (DIC)), embedded optical fibre sensors offer the advantage of being able to monitor local internal strains in the composite readily. Moreover,
FBG sensors offer the capability to accurately monitor resin flow front progression during infusion. ${ }^{14,23,24}$

This study focuses on investigating the development of internal strains in glass FRP (GFRP) composites in a holistic manner during the composite life cycle using embedded FBG sensors. The term life cycle in this context refers to the composite life time from manufacturing using vacuum infusion and until mechanical testing, as illustrated in Figure 1. Thus, using this approach, we wish to monitor the development of process-induced internal strains and investigate the influence of these strains and residual stresses in the composite during manufacturing and testing. This study provides an approach to monitor and gain knowledge during the manufacturing procedure of FRP composites. Such manufacturing control is important if consistency in the quality of the composite is desired. In addition, information of the residual strain and stress state in the structure is important if these are to be accounted for in the design of a structural component.

\section{FBG sensor principle}

Strain monitoring using optical fibres with FBG sensors requires a light source, an interrogator unit and an appropriate data acquisition software tool. The light source transmits a broadband light spectrum through the optical fibre and the axially placed FBG sensor back-reflects light within a specific pre-defined wavelength. This back-reflected light is fed into the interrogating unit designed to measure the reflected light signal. Modulation of the reflected signal, centred along the Bragg wavelength, is linearly related to mechanical or thermal loads. The FBG wavelength variation is hence determined using ${ }^{13}$

$$
\frac{\Delta \lambda_{B}}{\lambda_{B}^{0}}=K_{\epsilon}\left[\Delta \varepsilon_{a p p}^{\text {host }}+\Delta \varepsilon_{t h}^{\text {host }}\right]+K_{T} \Delta T=K_{\epsilon} \Delta \varepsilon_{t o t}+K_{T} \Delta T
$$

where $\Delta \lambda_{B}$ is the change in Bragg grating wavelength and $\lambda_{B}^{0}$ the initial unstrained grating wavelength, $K_{\epsilon}$ and $K_{T}$ are the optical fibre mechanical strain and temperature sensitivities, specific for the type of sensor used. $\Delta \varepsilon_{t o t}$ is the change in total strain - a summation of the increments from the applied strain $\Delta \varepsilon_{a p p}^{\text {host }}$ and the host thermal strain $\Delta \varepsilon_{t h}^{h o s t}$. Equation (1) describes the linear mechanical and thermal response of the FBG sensor. When the FBG is embedded in a composite material, here on termed the host material, complete strain transfer is achieved once bonding between the optical fibre and the host material occurs. Subsequently, any mechanical straining and thermal expansion of the host material would govern the response of the FBG sensor. Knowing the temperature 


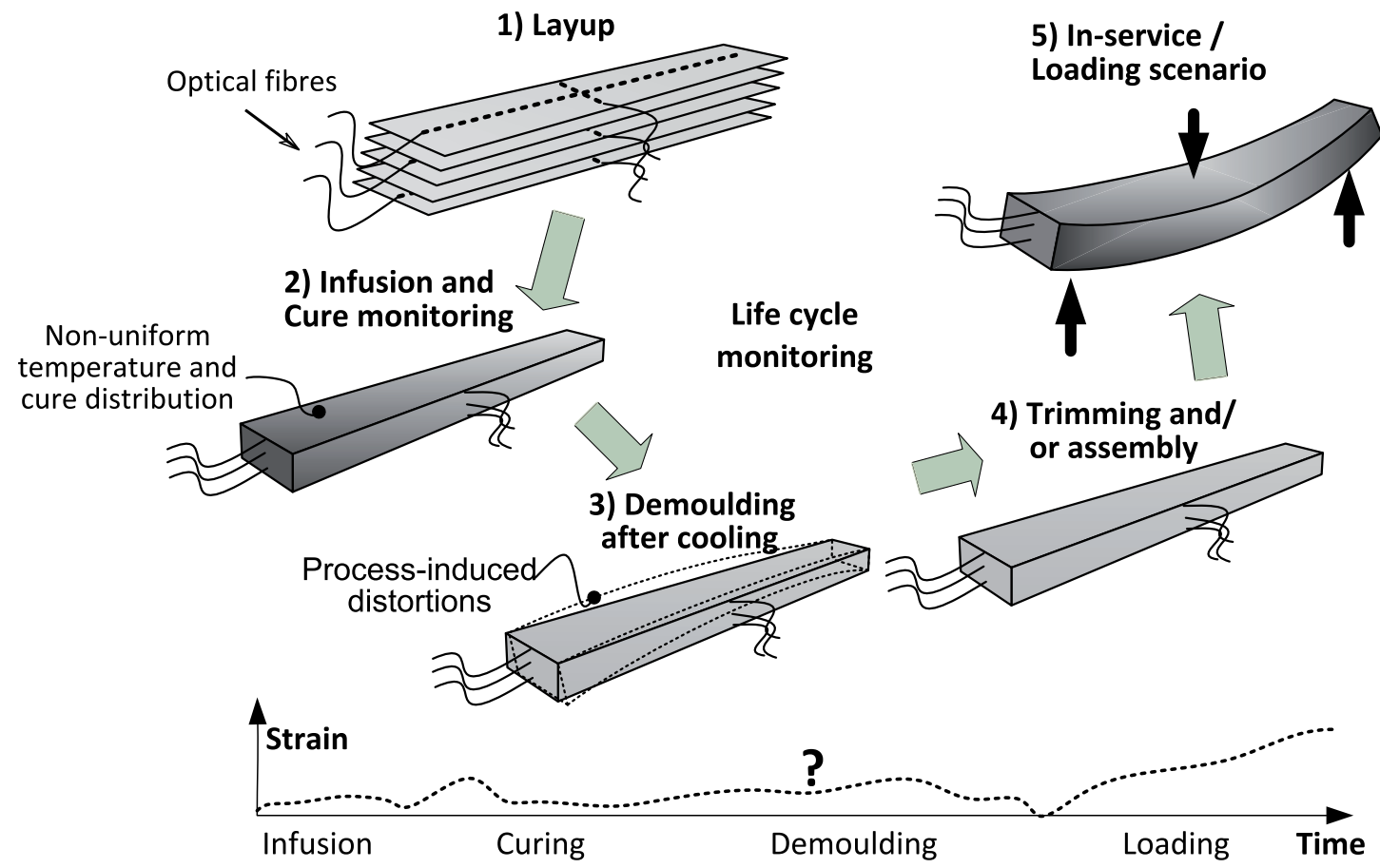

Figure I. Schematic of life cycle monitoring approach for a GFRP laminate using embedded optical fibres where internal strains are monitored from manufacture to loading.

GFRP: glass fibre reinforced polymer.

and sensor wavelength variation, the corresponding change in host material total strain in the optical fibre axial direction can be determined using equation (1) by isolating $\Delta \varepsilon_{\text {tot }}$.

In this study, silica optical fibres provided by FOS\&S, Belgium, were used, with multiple draw tower grating $\left(\mathrm{DTG}^{\circledR}\right)$ FBG sensors with an Ormocer $^{\circledR}$ coating (cladding diameter $125 \mu \mathrm{m}$ ). The sensitivity coefficients $K_{\epsilon}$ and $K_{T}$ are equal to $0.775 \mathrm{E}-$ $6 \mu \varepsilon^{-1}$ and $6.27 \mathrm{E}-6^{\circ} \mathrm{C}^{-1}$, respectively. When considering the magnitudes of the mechanical strain and temperature sensitivity coefficients, it is clear that accurate temperatures at the vicinity of the sensors is needed in order to determine precise strains. It has been shown that the strain sensitivity remains constant below $180^{\circ} \mathrm{C}$ for this optical fibre. ${ }^{20}$ Furthermore, DTG FBGs are known to exhibit little variation in strainoptic coefficients when loaded which is advantageous. The Ormocer coating helps reduce the sensor sensitivity to external transverse loading, hence increasing the accuracy of the axial strain measurements. An I-MON E interrogator, from Ibsen Photonics, Denmark, was used for data acquisition. The I-MON E is a standalone interrogation monitor with a wavelength bandwidth of $85 \mathrm{~nm}$, capable of assessing $<70 \mathrm{FBG}$ sensor signals. The interrogator wavelength accuracy lies within $5 \mathrm{pm}$ with a sampling rate of up to $970 \mathrm{~Hz}$. The grating length used in this work, i.e. the effective strain measurement region, spans $4 \mathrm{~mm}$ of the optical fibre length at each sensor positioned along the optical fibre. In other works, where a similar length is used, no peak splitting of the back-reflected wavelength spectrum was experienced. ${ }^{21,22}$ Peak-splitting is generally attributed to the existence of transverse loading of the sensor causing a local distortion of the reflected signal spectra. This is most likely to occur when using long gratings where a large transverse local load is present in the vicinity of the FBG sensor. By having a short grating length and using a coated fibre, this problem is greatly reduced. Studies found that good predictions of process strains in neat resin and composite laminates were achievable using a similar setup..$^{13,16,19}$

\section{Experimental procedure}

\section{Materials}

The composite constituent materials used in this study comprise of unidirectional (UD) fibre reinforcement fabric type L1200/G50F-E06-A, from Devold AMT, with a nominal area weight of $1246 \mathrm{~g} / \mathrm{m}^{2}$ and a thermoset epoxy resin matrix material type Airstone $760 \mathrm{E}$ mixed 100:32 parts-by-weight with Airstone 776H hardener, from Dow Chemicals Company. The reinforcement fibre and resin matrix material used in this study are representative of materials commonly 
used in commercial wind turbine blades. Material properties are summarised in Table 1. As mentioned in the introduction, epoxy resins exhibit volumetric chemical shrinkage during cross-linking, generally known to lie between $3 \%$ and $7 \% .^{9-11}$ Both constituent materials used exhibit isotropic thermal expansion behaviour, as observed from Table 1.

\section{Manufacturing procedure}

In order to investigate the influence of the cure cycle profile and boundary conditions on the process-induced strain development and subsequent part performance, two different manufacturing procedures were employed, as summarised in Figure 2 and Table 2. The tool used was a transparent tempered glass plate, chosen in order to visibly ensure full wetting of the reinforcement fibres during infusion. Vacuum infusion was performed as edge infusion with resin flow in the longitudinal fibre direction in the entire length of the specimens. An Enka channel mesh and highly porous distribution net (Figure 2) are used in order to allow fast flow along the top surface of the reinforcement fabric and subsequent through-thickness wetting. Fibre layup was established using 22 layers of UD glass fibre fabric each cut to $500 \times 100 \mathrm{~mm}^{2}(l \times b)$ and stacked symmetrically on the glass tool with the fibre backing material faced outwards. During the layup procedure, placement of optical fibres and

Table I. Material properties of E-glass reinforcement fibre and epoxy resin.

\begin{tabular}{lllll}
\hline \multicolumn{5}{c}{ Young's } \\
& $\begin{array}{l}\text { Density } \\
\left(\mathrm{kg} / \mathrm{m}^{3}\right)\end{array}$ & $\begin{array}{l}\text { modulus } \\
(\mathrm{GPa})\end{array}$ & $\begin{array}{l}\text { Poisson's CTE } \\
\text { ratio }\end{array}$ & $\left(\times 10^{-6 \circ} \mathrm{C}^{-1}\right)$ \\
\hline UD E-glass fibre & 2600 & $72.0^{\mathrm{a}}$ & 0.22 & $5.04^{\mathrm{a}}$ \\
Epoxy resin (cured) & 1040 & 3.116 & $0.32^{\mathrm{b}}$ & $65.4 \mathrm{I}^{\mathrm{b}}$ \\
\hline
\end{tabular}

CTE: coefficient of thermal expansion; UD: unidirectional.

alsotropic for E-glass.

${ }^{b}$ Approximated value from the literature.

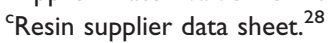

thermocouples was conducted as described in the subsequent section. After layup, a vacuum leak test was carried out prior to infusion. The epoxy resin was mixed with the hardener and degassed in a vacuum chamber with a vacuum pressure above $95 \mathrm{kPa}$, until all foaming had subsided. Infusion was carried out at ambient temperature with a vacuum pressure of $95 \mathrm{kPa}$. The inlet hose was closed once resin flowed through the outlet hose and full impregnation of the reinforcement fibres was visible. Full wetting of the reinforcement fibres took approximately $45 \mathrm{~min}$. The vacuum pressure was then reduced to $60 \mathrm{kPa}$ and pressure equalisation and further compaction of the laminate was allowed for $15 \mathrm{~min}$ before the outlet was closed. The vacuum infused specimens were placed into pre-heated ovens at $50^{\circ} \mathrm{C}$ and $80^{\circ} \mathrm{C}$ for approximately 5 and $3 \mathrm{~h}$, respectively, for the different cure cycles investigated (Table 2). The in-mould cure periods were chosen such that the resin was nearly fully cured based on differential scanning calorimetry isothermal scan data at various temperatures. Different cure temperatures were chosen in order to achieve different thermal residual stresses.

Table 2. Experimental design matrix showing layup, cure schedules and boundary conditions.

\begin{tabular}{lll}
\hline & Type A & Type B \\
\hline Layup & {$[0]_{22}$} & {$[0]_{22}$} \\
Cure temperature ${ }^{\mathrm{a}}\left({ }^{\circ} \mathrm{C}\right)$ & 50 & 80 \\
Temperature hold $^{\mathrm{b}}(\mathrm{min})$ & 300 & 180 \\
Cooling & Natural & Natural \\
& convection & convection \\
Post-cure temperature ${ }^{\mathrm{a}}\left({ }^{\circ} \mathrm{C}\right)$ & 90 & - \\
Post-cure hold $^{\mathrm{b}}(\mathrm{min})$ & 120 & - \\
Tool/part interface & Release agent & Perforated \\
& & release foil
\end{tabular}

${ }^{\text {a }}$ Pre-heated oven temperature.

${ }^{\mathrm{b}}$ Temperature hold period includes heating from ambient- to pre-heated oven temperature.

${ }^{\mathrm{c}}$ The tool surface was treated with release agent prior to the experiments.

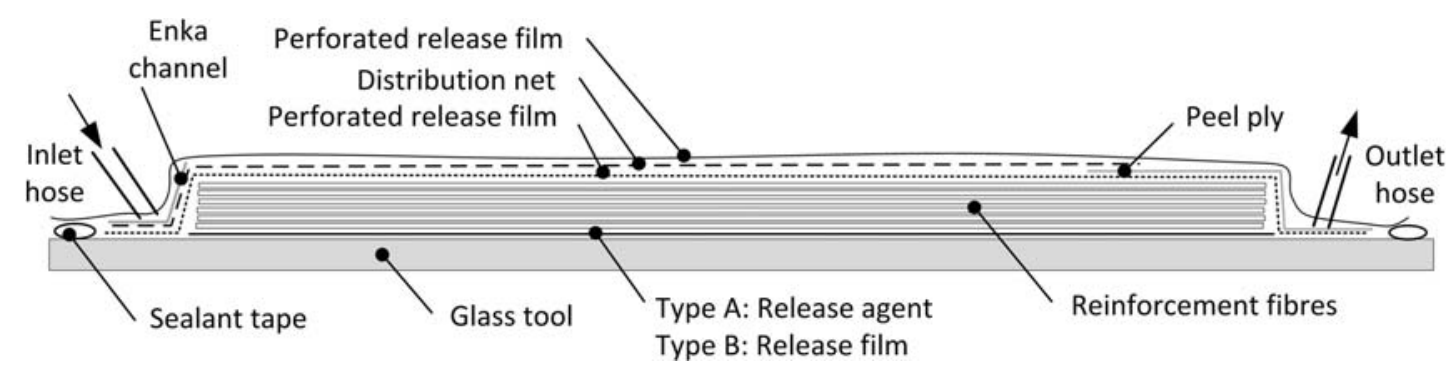

Figure 2. Schematic of vacuum infusion setup. 
The cured in-mould laminates were cooled by natural convection to ambient temperature. Cooling in this manner took approximately $3.5 \mathrm{~h}$ and $5.5 \mathrm{~h}$, respectively, for the $50^{\circ} \mathrm{C}$ and $80^{\circ} \mathrm{C}$ cure cycles. After cooling, demoulding was carried out and type A specimens were post-cured in a pre-heated oven at $90^{\circ} \mathrm{C}$ for $2 \mathrm{~h}$. Type B specimens were not post-cured. All specimens were then cut into $500 \times 45 \mathrm{~mm}^{2}(l \times b)$ beams. Trimming of the beam sides was done in order to ensure a constant cross section of each specimen, necessary in the mechanical tests. The manufactured specimens had a final average thickness of $19.04 \mathrm{~mm}$ with a variation of approximately $0.20 \mathrm{~mm}$, and a fibre volume fraction of approximately $55 \%$.

During manufacturing, two different tool/part interfacial interactions were investigated using release agent and release film (Table 2). This was done to investigate non-uniform through-thickness strain variations during manufacturing as well as the possible occurrence of locking. ${ }^{11} \mathrm{~A}$ total of 10 laminates were manufactured using the different cure cycle and boundary conditions summarised in Table 2 evenly divided between the specimens.

\section{Optical fibre and thermocouple sensor embedment}

During the layup process, optical fibres consisting each of three FBG sensors were placed in the laminate, as illustrated in Figure 3. The optical fibres were placed along the UD reinforcement fibre direction (i.e. longitudinally) as well as perpendicular to the reinforcement fibres (transversely). This was done at three different interlayer locations along the ply stack thickness direction: between the 1st and 2nd, 11th and 12th and 21st and 22nd plies representing the laminate beam specimen top, middle and bottom planes (Top, Mid and Bot henceforth). In order to ensure that the optical fibres remained in place, they were sewn in place using the backing fibres of the reinforcement fibre fabrics, as an alternative to using adhesives, etc. In this manner, the optical fibres remained aligned but at the same time not entirely constrained. Temperature monitoring during processing was conducted using type-J (Fe-CuNi) $2 \times 0.5 \mathrm{~mm}$ thermocouples, placed at various regions on the outer surface and within different layers approximately $10 \mathrm{~mm}$ from the edge of the laminate. Temperature data was collected using an eight-channel DaqPRO data acquisition system (Fourier systems, Barrington, USA), with a sampling frequency of $10 \mathrm{~Hz}$. Data logging were commenced once infusion was initiated, as well as at different intervals at ambient temperatures between the various manufacturing steps. Hence, information revealing the internal strain development at discrete times throughout the manufacturing process was obtained from the specimens at different through-thickness layers in different reinforcement fibre directions. Strain and temperature monitoring was carried out in three 'Type A' and two 'Type B' laminate beam specimens, respectively. The remaining laminate beams without embedded sensors were solely used for mechanical test verification purposes.

Temperature logging conducted during the experiments served two purposes. First, the temperatures are used in equation (1) in order to compensate for the thermal expansion of the optical fibre and determine the total mechanical strains from the FBG data. The thermocouples are also used to monitor the exothermic reaction of the resin during curing and ensure that the specimens were cooled to the ambient temperature at the data sampling intervals. Figure 4 shows some of the specimens manufactured at various stages during the experiments.

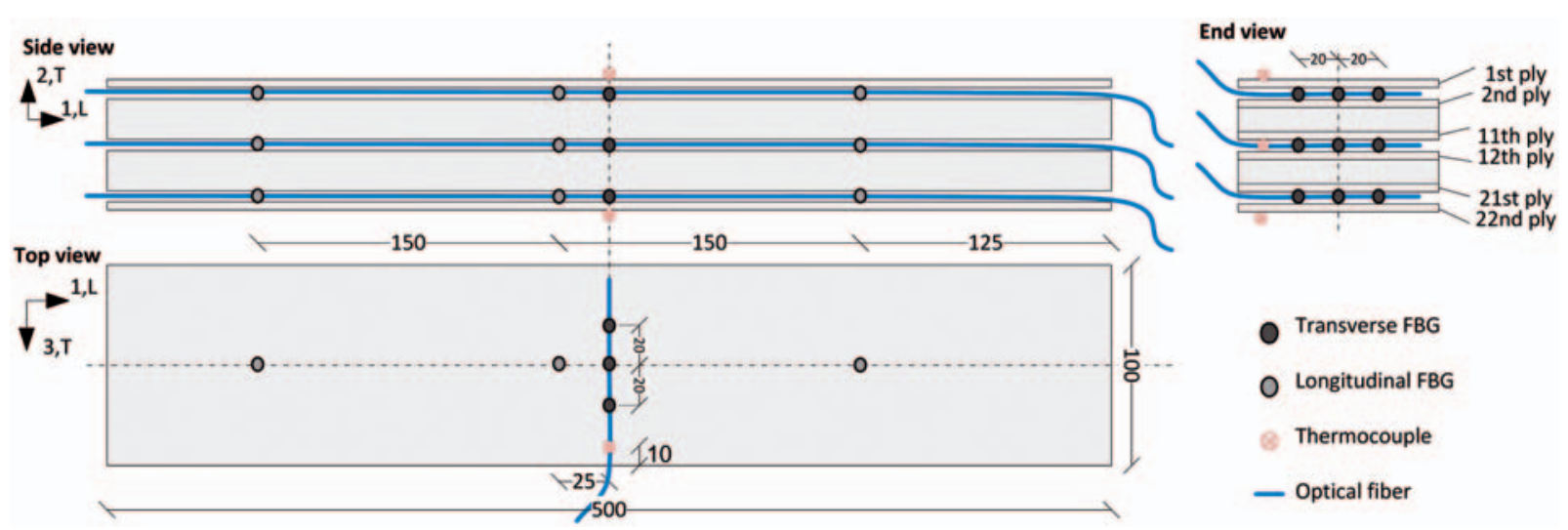

Figure 3. Schematic of laminate beam layup with FBG and thermocouple sensor placement. FBG: fibre Bragg grating.

All dimensions are in $\mathrm{mm}$. 


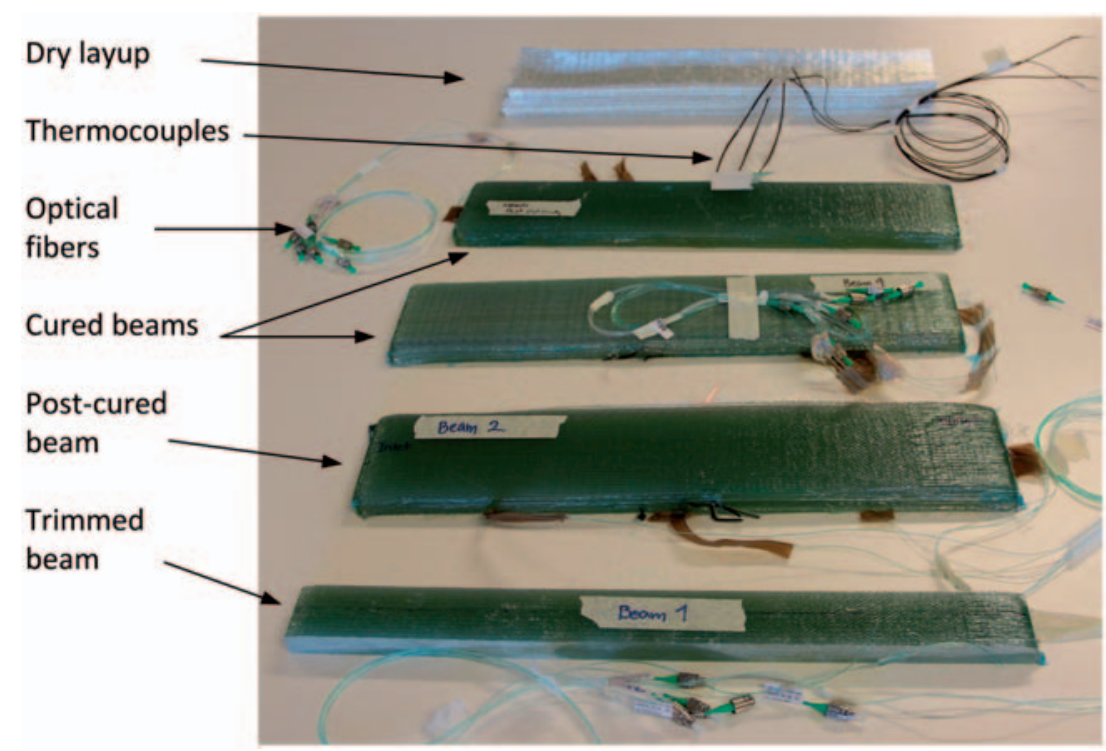

Figure 4. Laminate beam specimens at different stages in the manufacturing procedure, seen with embedded FBG sensors and thermocouples.

FBG: fibre Bragg grating.

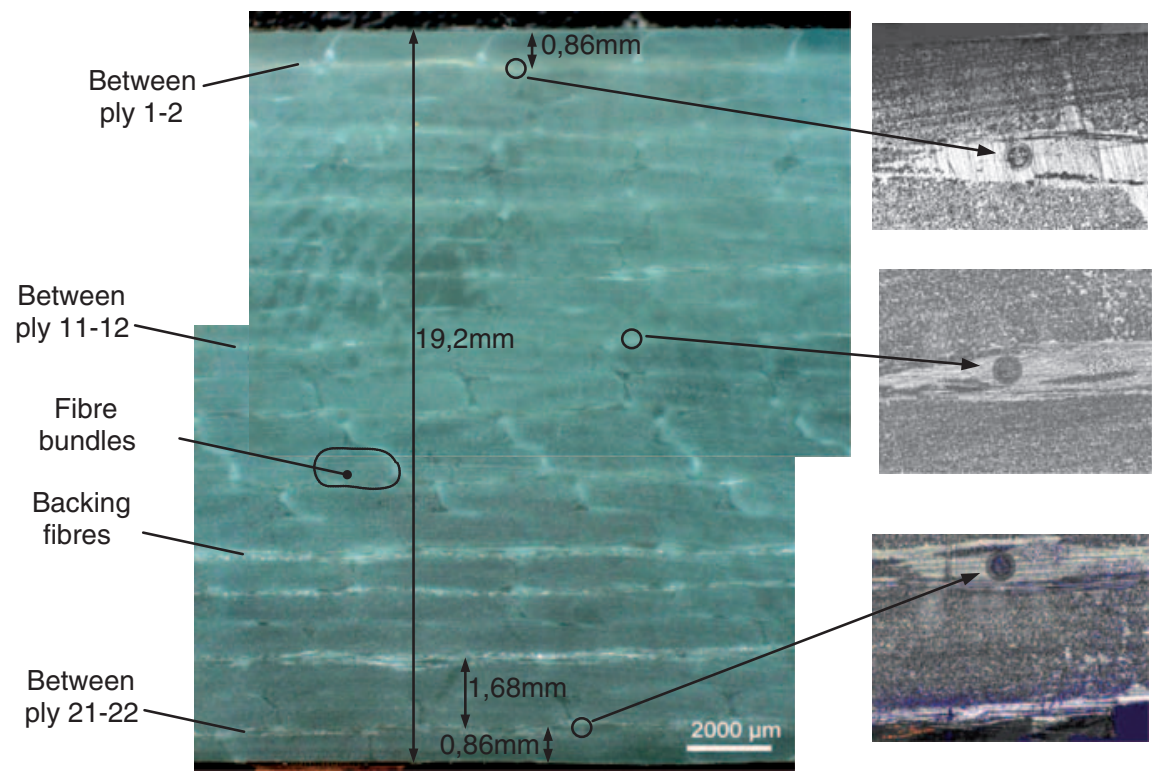

Figure 5. Image of laminate specimen cross section with close-up of inter-ply placement of optical fibres.

To ensure that the optical fibres remained at their respective laminate inter-ply locations during layup and vacuum infusion, a cross-sectional microscope analysis was conducted, after mechanical testing. Knowing the exact depth of each optical fibre is, for instance, vital for correct comparison of surface mounted SGs and embedded optical fibres. Figure 5 shows microscope images of the laminate beam cross section, showing placement of optical fibres after manufacturing. The optical fibres were found to be situated at the same inter-ply regions as during layup. It has been reported in some studies that standard $125 \mu \mathrm{m}$ optical fibres produce a insignificant perturbation of the host material when embedded parallel to the reinforcing fibres in laminates. ${ }^{25,26}$

\section{Experimental results and discussion}

\section{Strains at discrete periods during manufacturing}

Figures 6 and 7 show measured total strains at discrete periods during manufacturing for type $\mathrm{A}$ and $\mathrm{B}$ 


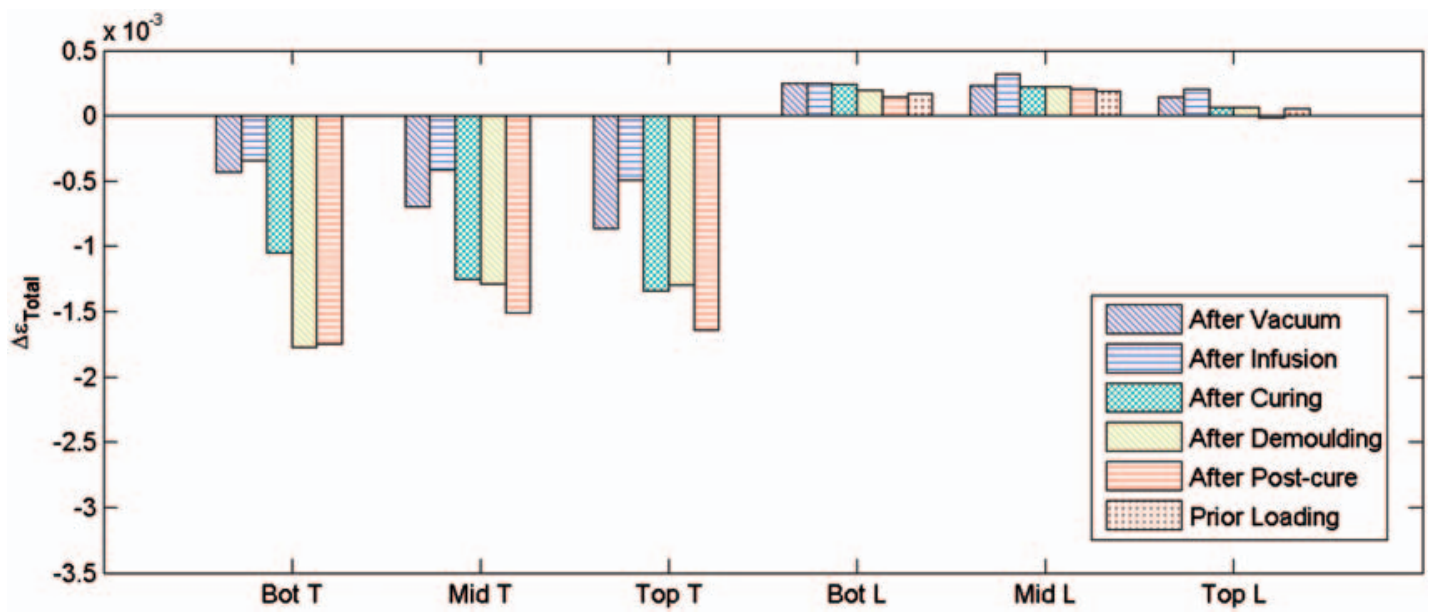

Figure 6. Average total strains at manufacturing intervals, measured at ambient temperature for type A laminate beam specimens.

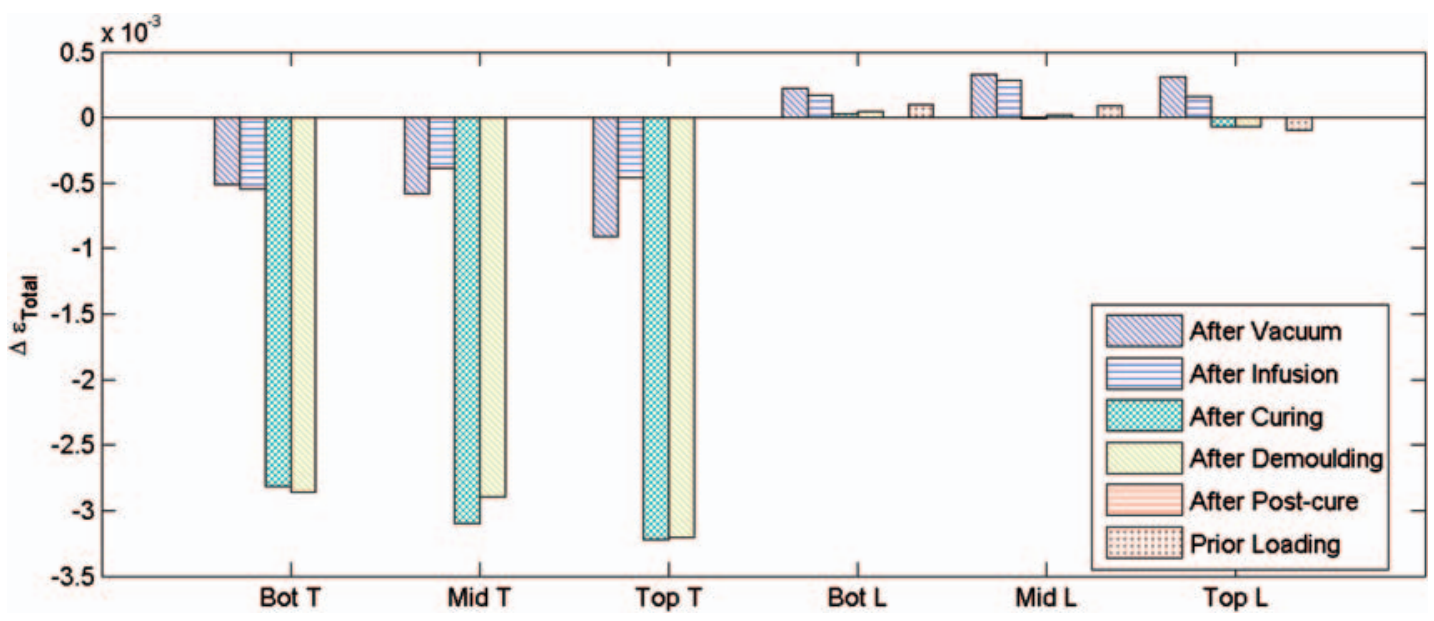

Figure 7. Average total strains at manufacturing intervals, measured at ambient temperature for type B laminate beam specimens.

laminate beams, respectively, at ambient temperature. The values presented are averages of type A and B specimens for all three FBG sensors on each optical fibre at discrete stages during manufacturing. Total strains are shown: (a) after vacuum pressure is applied; (b) after infusion (resin flow); (c) after curing; (d) after demoulding; (e) after post-curing (type A only); and finally (f) prior loading. Note that the transversely embedded optical fibres were no longer usable after cutting, hence no transverse measurements are conducted prior loading.

In both cure cycle cases shown (Figures 6 and 7), transverse total strains which are matrix dominated are seen to have higher magnitudes as compared to the longitudinal strains, which are fibre dominated, i.e. more constrained. General tendencies are as follows: upon applying vacuum pressure, a negative increment in strains are seen in the transverse direction, while a small positive increment in tensile strains arise in the longitudinal direction (here onwards $T$ - and $L$ directions). The elongation longitudinally is believed to be due to re-alignment of fibres from a wavy to straight state when under pressure effectively straining the optical fibre in tension. After infusion, a slight decrease in strain magnitudes is exhibited in general. After curing, a significant negative strain increment in the $T$-direction occurs in type A and B specimens throughout the beam thickness, as well as a slight negative strain increment in the $T$-direction. This is an indication of prevailing compression/shrinkage due to the inherent mechanisms present, i.e. matrix shrinkage and thermal compression upon cooling. A significant difference in strain magnitudes after curing is seen between type A and B specimens, with larger negative strains in type B specimens. Assuming that both specimens are fully cured such that total chemical shrinkage has taken place, the difference in magnitudes owes to larger thermally induced strains in type $\mathrm{B}$ beams. The through-thickness strain 
distribution in both cases is largest near the top surface as compared to at the tool/part interface (Bot) where tool/part interaction constrains movement. Upon demoulding, a larger strain release is exhibited at Bot $\mathrm{T}$ in type $\mathrm{A}$ specimens, as opposed to Bot $\mathrm{T}$ in type $\mathrm{B}$ beams. This is an indication that better bonding at the tool/part interface existed during curing when release agent is used at the tool/part interface as opposed to when using the perforated release foil.

Figure 8 shows the total strains for type A and B beams in the $L$ - and $T$-directions compared to each other. Results are shown for stages after curing, where it is assumed that perfect bonding between the composite and optical fibre exists. After curing, a nonuniform strain distribution through the thickness is seen in both $L$ - and $T$-directions. After demoulding, negative strain increments are seen at the laminate bottom plane in the $T$-direction for both beam types (Figure 8 (T-2)), indicating a tensile stress state at the bottom laminate plane after curing. This implies that a compressive stress state exists at the laminate centre while tensile stresses exist at the surfaces, which is a common stress state when an inside-out cure occurs due to exothermic peak temperatures at the centre, as also seen in Bogetti and Gillespie. ${ }^{3}$ Moreover, for type B specimens, this is also seen at the top plane, while at the middle plane a positive strain increment is seen. When considering the through-thickness strain gradients, a more uniform distribution is generally seen in type B specimens. This indicates that weaker bonding at the tool/part interface exists when using release film, allowing for more sliding friction behaviour. This observation is supported by the fact that all type B specimens were significantly easier to separate from the glass tool during demoulding.

When considering the free-standing change in type B longitudinal strains from demoulding and prior loading (Figure 8 (L-2 to L-4)), an increase in tensile strains is seen near the beam bottom plane. This is due to viscoelastic creep, exhibited by the composite during the 6 week period in time before loading tests were commenced. Contrary to this, a decrease in tensile strains (compressive creep) is seen for type A beams after postcuring and prior loading. Positive creep strains indicate

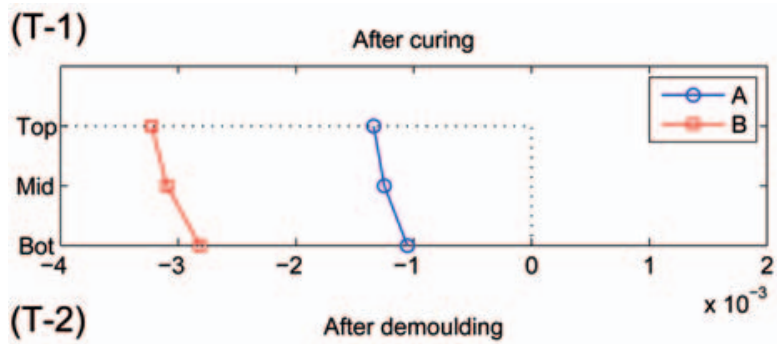

$(L-1)$

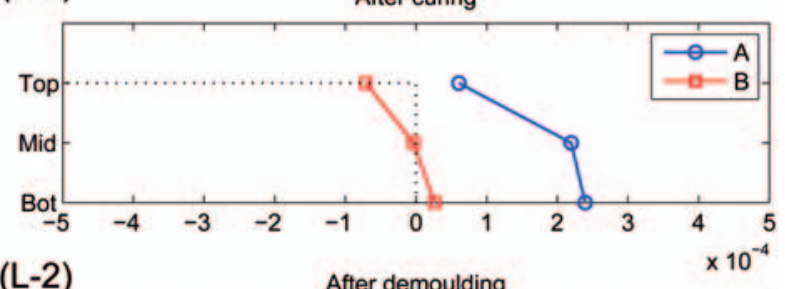

(L-2)

After demoulding

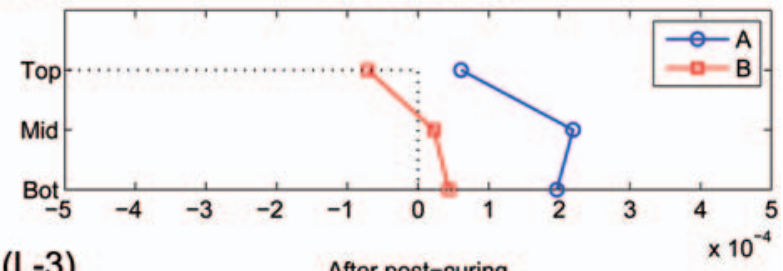

(L-3) After post-curing
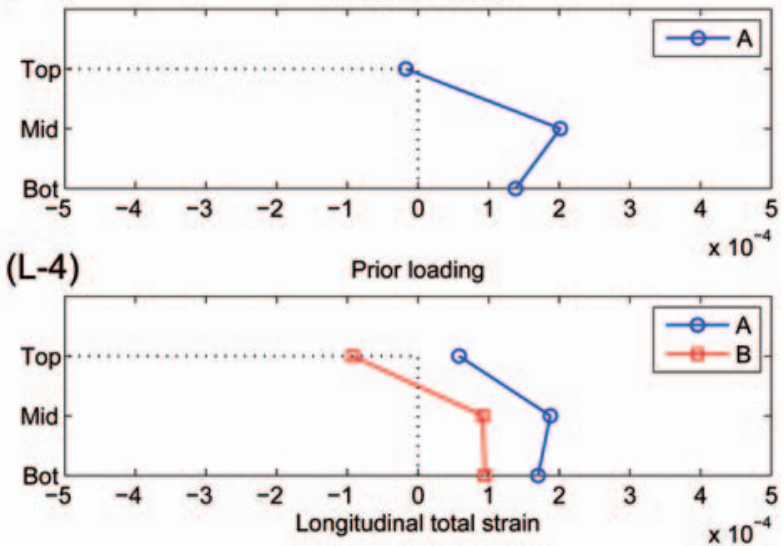

Figure 8. Average laminate type $A$ and $B$ transverse $(T)$ and longitudinal $(L)$ strains after various manufacturing stages compared to non-strained (dashed line) laminate beam state. 
that a compressive stress state exists, that is not readily released as distortions after curing, but gradually with time. Nedele and Wisnom ${ }^{7}$ and Wisnom et al. ${ }^{11}$ found that residual stresses at a micromechanic level may not normally readily cause distortions because they may arise at a very local scale, where any deforming effects are averaged out over the larger volume of material. Hence inter-ply or microscale compressive stresses may still exist in the beams.

\section{Strain monitoring signal quality}

The quality of the strain measurements was monitored during this study by constant evaluation of the reflected light signal spectrum. This is presented for a type B laminate after curing at ambient temperature in Figure 9, compared to the reflected signal prior vacuum-bagging and infusion for longitudinally and transversely embedded FBG sensors. Due to the large compressive strains in the transverse direction after curing, the signal peaks have been shifted left to lower wavelength values. Furthermore, some distortion of the FBG spectrum is seen in the form of birefringence (peak splitting) of the Bragg peak. The peaksplitting seen indicates development of transverse loads at the vicinity of the sensors. ${ }^{13,18}$ This could be the result of backing-fibres or perpendicular UD fibre bundles that are locally loading the optical fibres not to mention resin shrinkage stresses around each optical fibre (Figure 10). Broadening of the spectrum is also

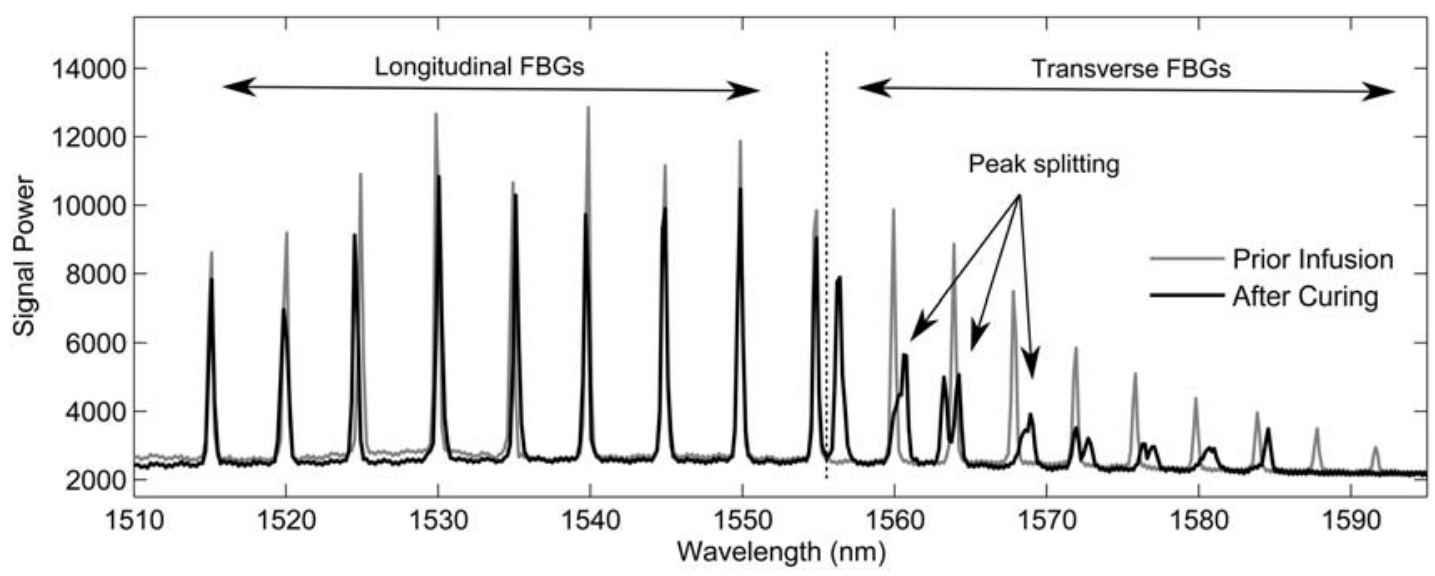

Figure 9. Wavelength signal spectrum for type B laminate after curing, showing clear signs of birefringence of the light signal (peak splitting).

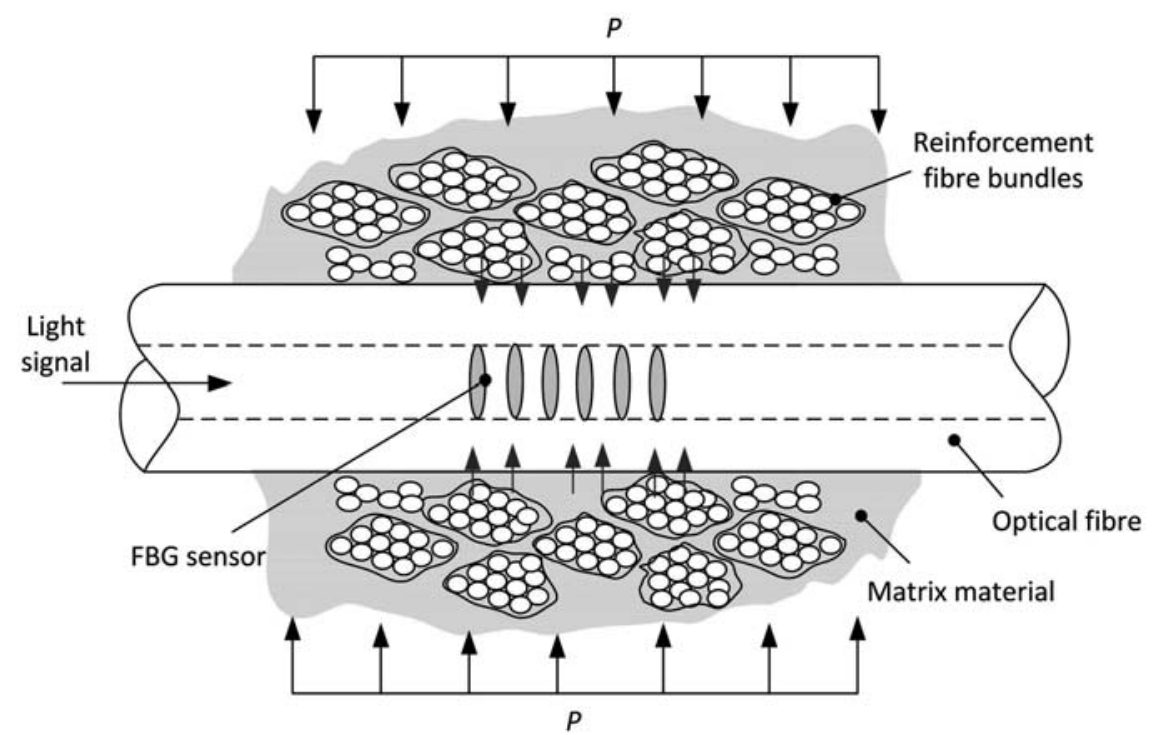

Figure 10. Illustration of mechanisms causing transverse loading of optical fibre from reinforcement fibre tows perpendicular to the optical fibre during processing. 
observed, which is also an indication that transverse stress may exist. ${ }^{13}$ Distortion is not seen in any of the signals from longitudinal sensors, but only in Type B transverse signals. Acquiring the correct discrete wavelength shift in order to determine the mechanical strain variation must, therefore, be interpreted with caution where peak-splitting of the signal is present. The data acquisition software seeks only the signal peaks above a user-defined threshold found using an $n$ th-order polynomial fit for a prescribed number of expected peak signals (here 18). In this study, in order to account for these signal distortions, an approach is used where averaging of multiple peaks within a common base is performed for the discrete ambient strains presented in the previous section. The spectrum data shows that larger stresses are generally present in Type B specimens as opposed to Type A.

\section{In situ strains during infusion}

Flow front monitoring is conducted during resin infusion by monitoring the shift in wavelength of the embedded FBG sensors during vacuum infusion. Figures 11 and 12 show the strain variations during infusion for a beam specimen representative of general tendencies occurring in the $L$ - and $T$-directions, respectively.

After approximately $100 \mathrm{~s}$, infusion is commenced and the resin flow front reaches the L-embedded sensors near the inlet first, seen as changes in sensor 3 wavelengths at the top, mid and bottom (Figure 11). As the flow front progresses along the laminate top surface and gradually through the thickness towards the outlet, changes in wavelengths are seen in the Lembedded sensors and the corresponding T-embedded sensors (Figure 12). Hence, at different times during

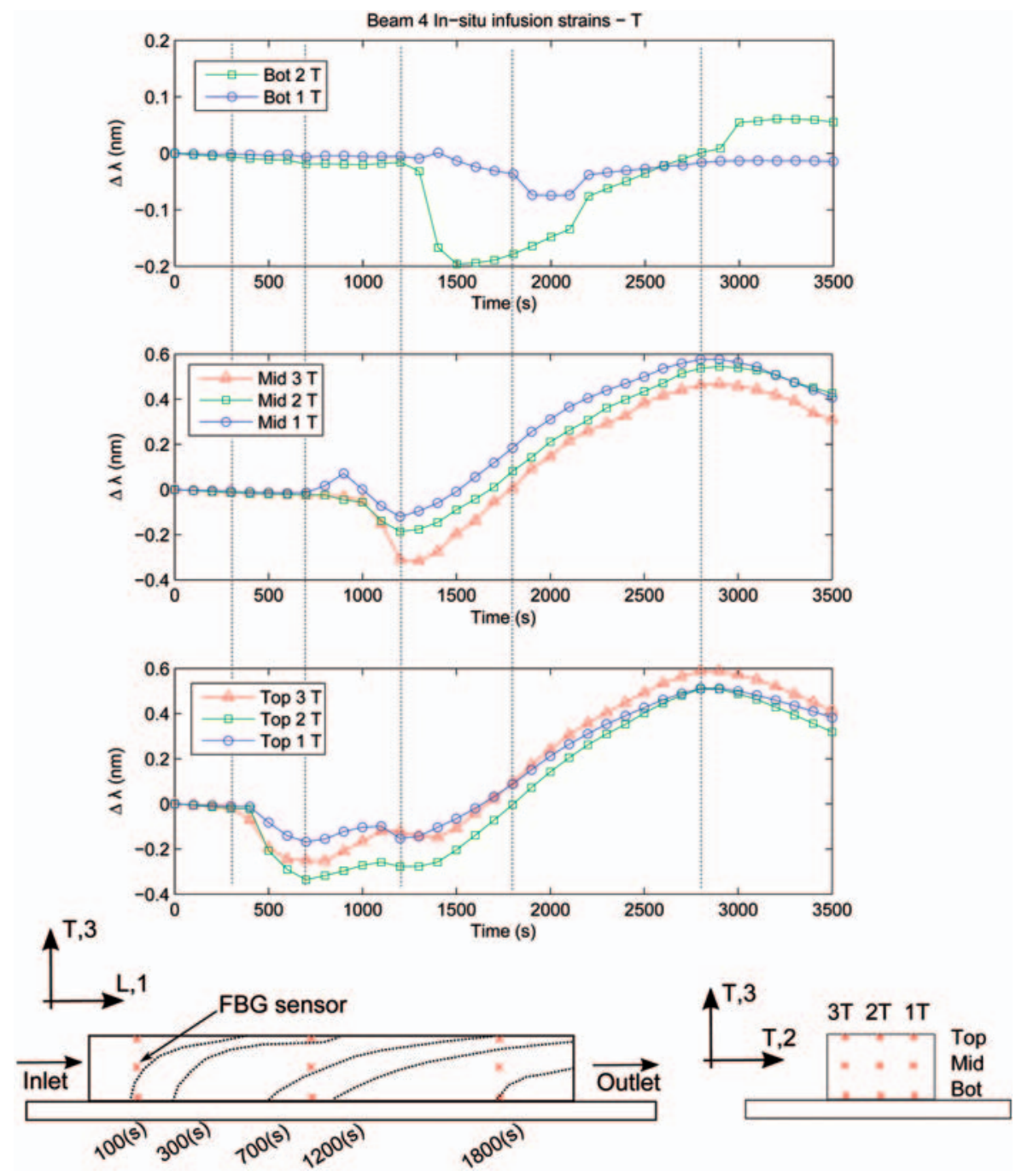

Figure II. Variations in longitudinally embedded FBG sensor wavelengths during infusion. Also seen is a schematic of the sensor placement from inlet to outlet and the expected flow front development. FBG: fibre Bragg grating. 
infusion, through-thickness tracking of the resin flow front in different directions is possible. After approximately time $t=2800 \mathrm{~s}$, the inlet hose is closed, marked by changes in wavelength in all embedded sensors as the flow speed is drastically reduced.

\section{In situ strains during curing}

In Figure 13, experimentally measured temperatures for type A and B cure cycles are presented. A gap in the acquired type A temperature data is seen between time $t=180$ and $300 \mathrm{~min}$. For the sake of continuity, estimated temperature development curves are drawn, following tendencies from type B data. In both cases, the exothermic reaction during resin cross-linking as the matrix cures results in peak temperatures that are higher than the prescribed oven cure temperatures of $50^{\circ} \mathrm{C}$ and $80^{\circ} \mathrm{C}$ for type $\mathrm{A}$ and $\mathrm{B}$, respectively. The large increase in temperatures is accredited to high heat generation rates as the matrix cures. The peak exothermic
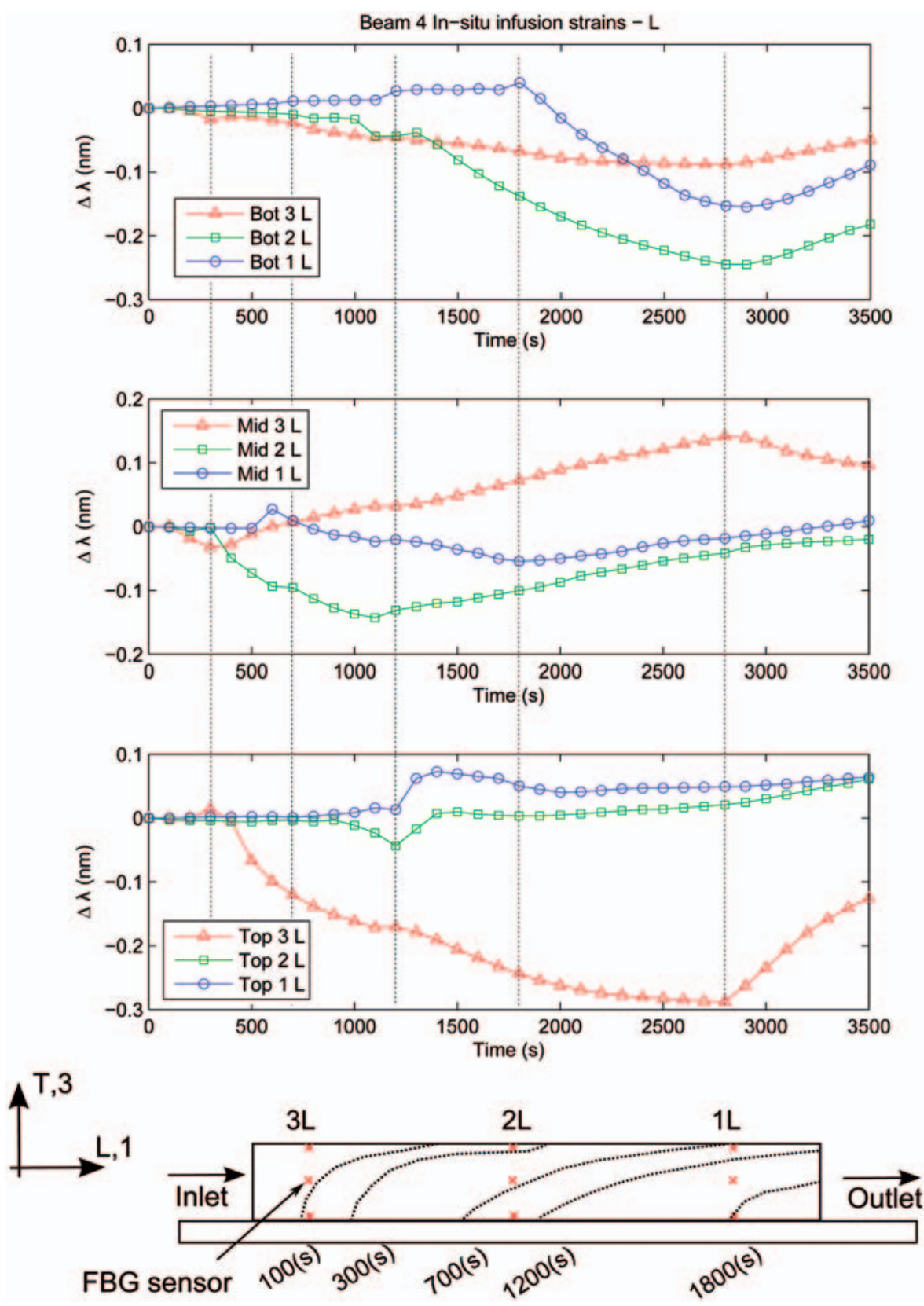

Figure 12. Variations in transversely embedded FBG sensor wavelengths during infusion.

Similarly, a schematic of the sensor placement is given and the expected flow front development, as shown in Figure II. FBG: fibre Bragg grating. 


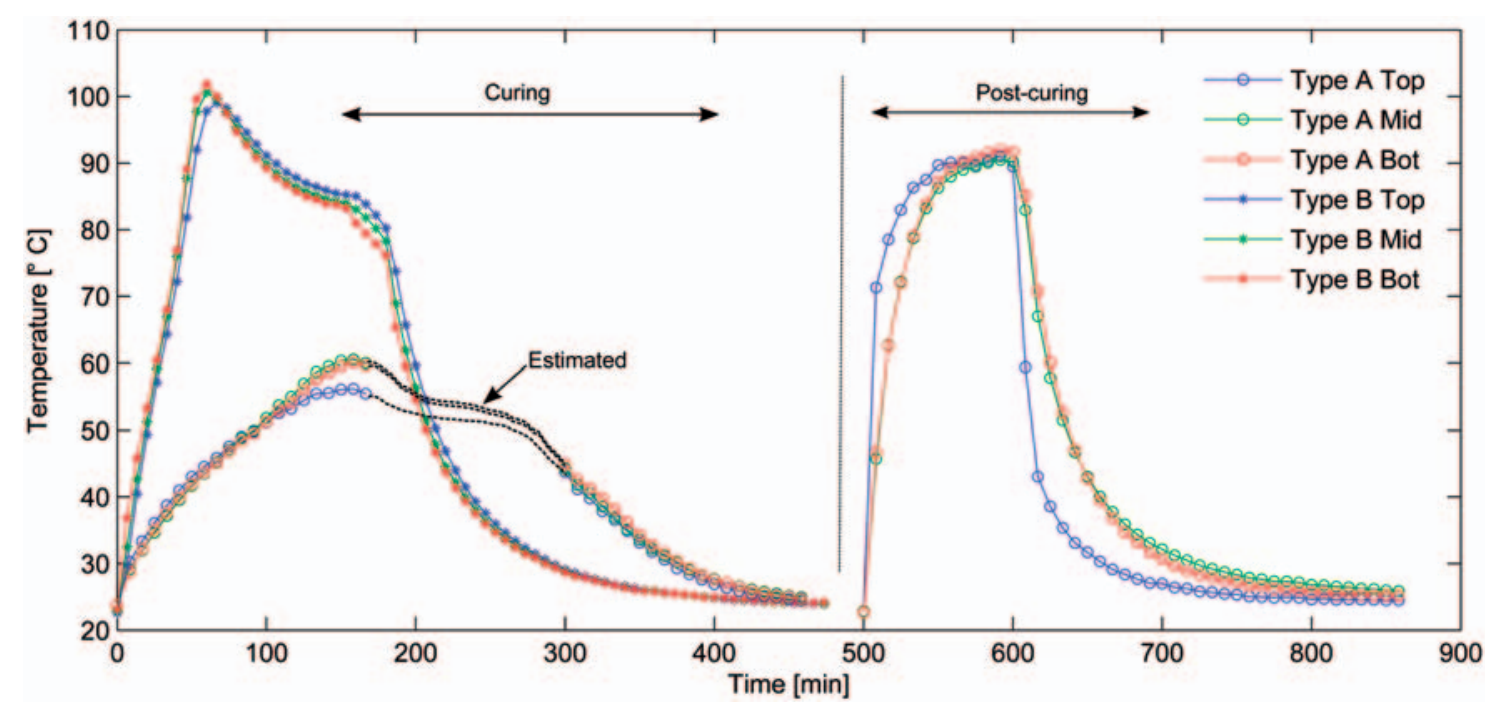

Figure 13. Temperature profiles for type A and B cure cycle laminate beam samples during curing. Note that only type $A$ specimens are post-cured.

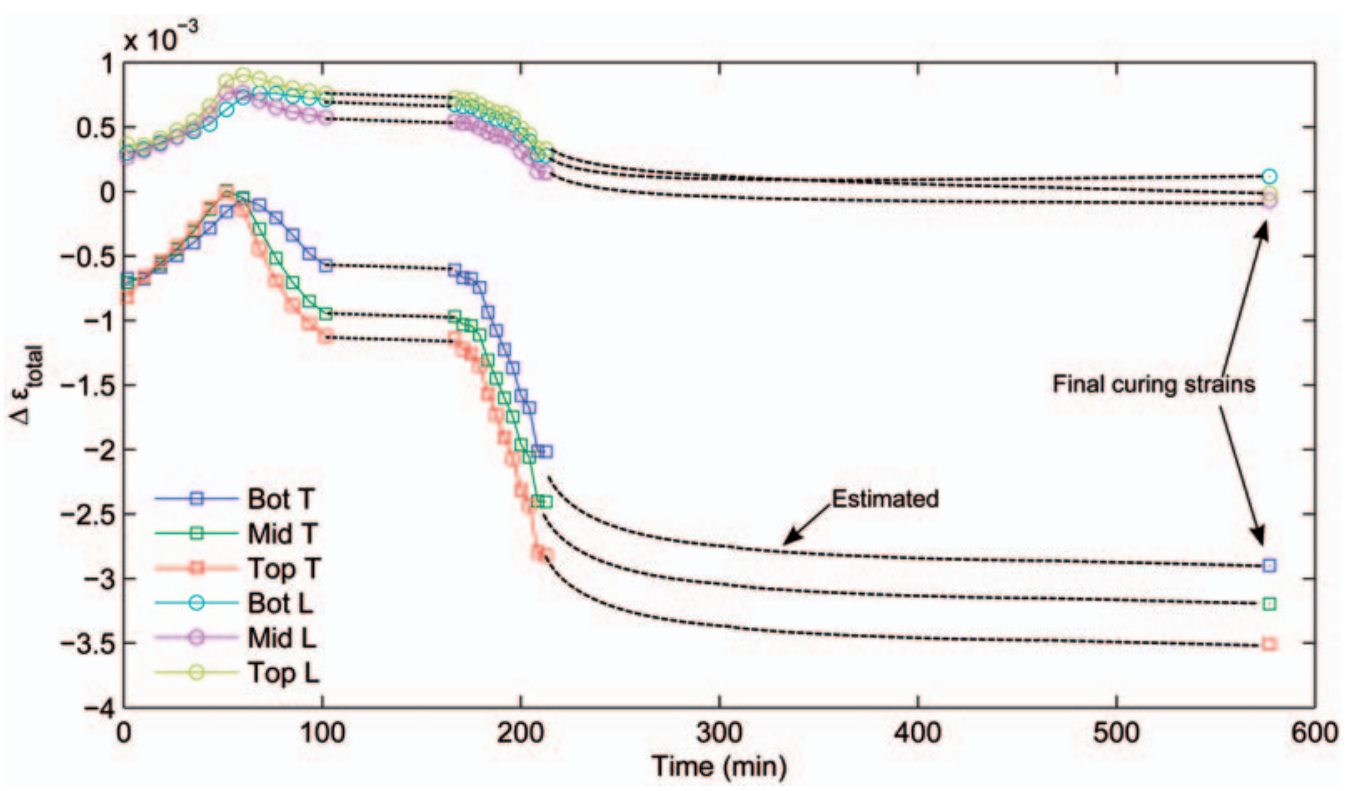

Figure 14. In situ total strain measurements during curing for type B specimen.

Dotted lines are added for continuity where loss of signal occurred.

temperatures are approximately $60.1{ }^{\circ} \mathrm{C}$ and $100.6^{\circ} \mathrm{C}$ during in mould cure, while the peak post-cure temperature is $98.3^{\circ} \mathrm{C}$ measured towards the end of the $90^{\circ} \mathrm{C}$ post-cure temperature hold for type A beam specimens. The peak temperatures are measured at the laminate mid-layer. The temperature peaks during post-curing is due to the release of residual latent heat which was not fully released during the first heating cycle.

In situ strain monitoring during curing is shown in Figure 14 for a type B beam using averaged values for top, mid and bot ( $\mathrm{T}$ and $\mathrm{L}$ ) sensor measurements as calculated using equation (1). Where loss of signal from the interrogator unit was encountered, dotted lines are added for the sake of continuity based on the temperature profiles observed from Figure 13 during cooling. The in situ strain development generally follows the temperatures for type B specimens well (Figure 13) depicting an increase upon heating, a peak, dwell and decrease in strains during cooling. Early in the process, thermal expansion- and chemical cure shrinkage strains occur simultaneously, resulting 
in negative strains after the exothermic reaction has occurred. This is mainly seen in the transverse (matrix driven) direction. In both the $L$ - and $T$-directions, the higher mechanical constraints at the bottom layer, in both $T$ - and $L$-directions, result in lower negative and positive strains, respectively, as compared to strain magnitudes at mid and top. Upon the onset of cooling after approximately $160 \mathrm{~min}$, negative strain increments in the $T$ - and $L$-directions are seen, owing primarily to thermal contraction, assuming the resin is fully cured and total chemical cure shrinkage has occurred. The strains after cooling are also shown, corresponding to the 'after curing' strains previously shown in Figures 6 and 7.

Simple analytic calculations based on the self-consistent field micromechanic model are made to validate the cure strain magnitudes found. The effective laminate longitudinal and transverse thermal strain increments can be calculated using ${ }^{3}$

$$
\begin{aligned}
\Delta & \varepsilon_{L}^{t h}=\left[\frac{\alpha_{f} E_{f} V_{f}+\alpha_{m} E_{m}\left(1-V_{f}\right)}{E_{1 f} V_{f}+E_{m}\left(1-V_{f}\right)}\right] \cdot \Delta T \\
\Delta \varepsilon_{T}^{t h}= & \left\{\left(\alpha_{f}+v_{12 f} \alpha_{f}\right) V_{f}+\left(\alpha_{m}+v_{m} \alpha_{m}\right)\left(1-V_{f}\right)\right. \\
& -\left[v_{12 f} V_{f}+v_{m}\left(1-V_{f}\right)\right] \\
& \left.\times\left[\frac{\alpha_{f} E_{f} V_{f}+\alpha_{m} E_{m}\left(1-V_{f}\right)}{E_{f} V_{f}+E_{m}\left(1-V_{f}\right)}\right]\right\} \cdot \Delta T
\end{aligned}
$$

where $E, \alpha$ and $v$ are the respective constituent modulus, coefficient of thermal expansion (CTE) and Poisson's ratio and $V_{f}$ the reinforcement fibre volume fraction. The subscripts $f$ and $m$ denote fibre and matrix specific quantities and $\Delta T$ the change in temperature. Assuming that the resin is in glassy state the instant the peak exothermic temperature is achieved, the temperature variation during the cooling phase (i.e. from the peak cure temperature to ambient) can be used to calculate the thermal strain increments. Results are summarised in Table 3.

The analytically determined transverse thermal strains coincide well with the experimentally determined FBG strain values, measured at the least constrained laminate layer, namely the top layer. A large discrepancy is seen when comparing the longitudinal strains, which could be due to the larger influence of the tool interaction along the length of the beam. It is believed that the poor agreement in analytical and experimental strains in the longitudinal fibre direction may generally owe to the positive pre-straining of the fibres in this direction once the vacuum pressure was applied and during infusion (Figures 6 and 7). Note that the analytical calculations do not take into account gelation, differential resin material CTE in rubbery and
Table 3. Analytical thermal strain increment during cooling compared to measured total strains at the laminate beam top plane.

\begin{tabular}{lll}
\hline & Type A & Type B \\
\hline$\Delta T\left({ }^{\circ} \mathrm{C}\right)$ & -38.6 & -79.6 \\
$\Delta \varepsilon_{L}^{\text {th }}$ & $-0.28 \mathrm{IE}-3$ & $-0.579 \mathrm{E}-3$ \\
$\Delta \varepsilon_{T}^{\text {th }}$ & $-1.80 \mathrm{E}-3$ & $-3.60 \mathrm{E}-3$ \\
$\Delta \varepsilon_{L}^{\text {tot }}-\mathrm{FBG}$ & $-0.06 \mathrm{E}-3$ & $-0.00 \mathrm{IE}-3$ \\
$\Delta \varepsilon_{T}^{\text {tot }}-\mathrm{FBG}$ & $-1.34 \mathrm{E}-3$ & $-3.50 \mathrm{E}-3$ \\
\hline
\end{tabular}

FBG: fibre Bragg grating.

glassy state or chemical shrinkage strains. If one wishes to accurately predict these effects, numerical process models could be used.

\section{Flexural tests - Three-point bending}

Although large process-induced strains were seen to develop in the $T$-direction during curing, only small strains were measured in the $L$-direction. Hence, large residual stresses in the $L$-direction may still exist that are not released into distortions upon demoulding or relaxed during post-curing. At a micromechanical level, resin cure shrinkage and contraction upon cooling result in a tensile stress state in the $L$-direction in the matrix, due to constraints posed by the reinforcement fibres. In turn, the reinforcement fibres are in a compressive stress state upholding equilibrium. Whether these residual stresses influence the composite mechanical behaviour during loading is investigated using simple flexure tests. Figure 15 shows a schematic of the flexure test beam samples and sensor placement.

The tests were conducted in a custom made threepoint test rig with adjustable rolling cylindrical supports (Figure 15), using an MTS 810 axial servohydraulic table top test, with a $\pm 180 \mathrm{~mm}$ stroke and force capacity of $25 \mathrm{kN}$. The loading and support nose cylinder diameters are 40 and $25 \mathrm{~mm}$, respectively. A large nose radius was used to avoid excessive indentations and failure due to stress concentrations directly under the loading point. The test rig is connected to the load cell and hydraulic piston by serrated grips. The piston is controlled through the MTS FlexTest system by a servo valve model $525-15 \mathrm{~A}-04$ with a maximum flow of $10 \mathrm{~L} / \mathrm{s}$ and load cell model 662.10A-05. A crosshead rate of $0.5 \mathrm{~mm} / \mathrm{min}$ is used and tests are conducted until a substantial drop in the specimen load-carrying capacity is exhibited. The strain at the top and bottom surface of the test specimen is acquired from four SG located at the top and bottom surface along the same beam cross section as the embedded FBG sensors (Figure 15). Strains are measured along the laminate 


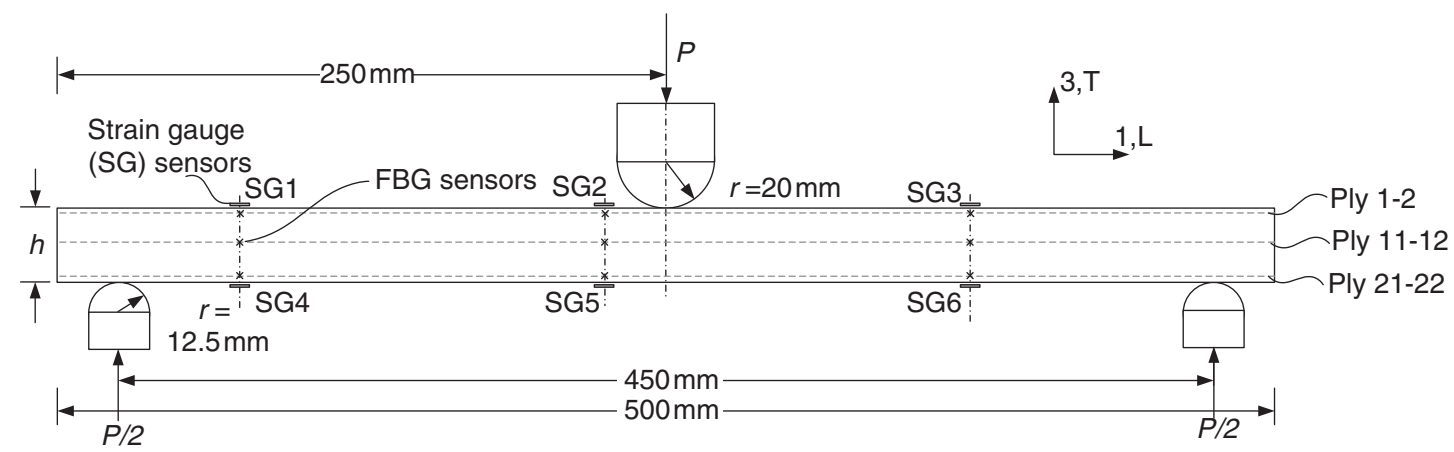

Figure I5. Schematic of three-point flexure test setup of laminate beam specimens.

Also seen are the embedded FBG fibres and SGs (SGI-SG4).

FBG: fibre Bragg grating; SG: strain gauge.
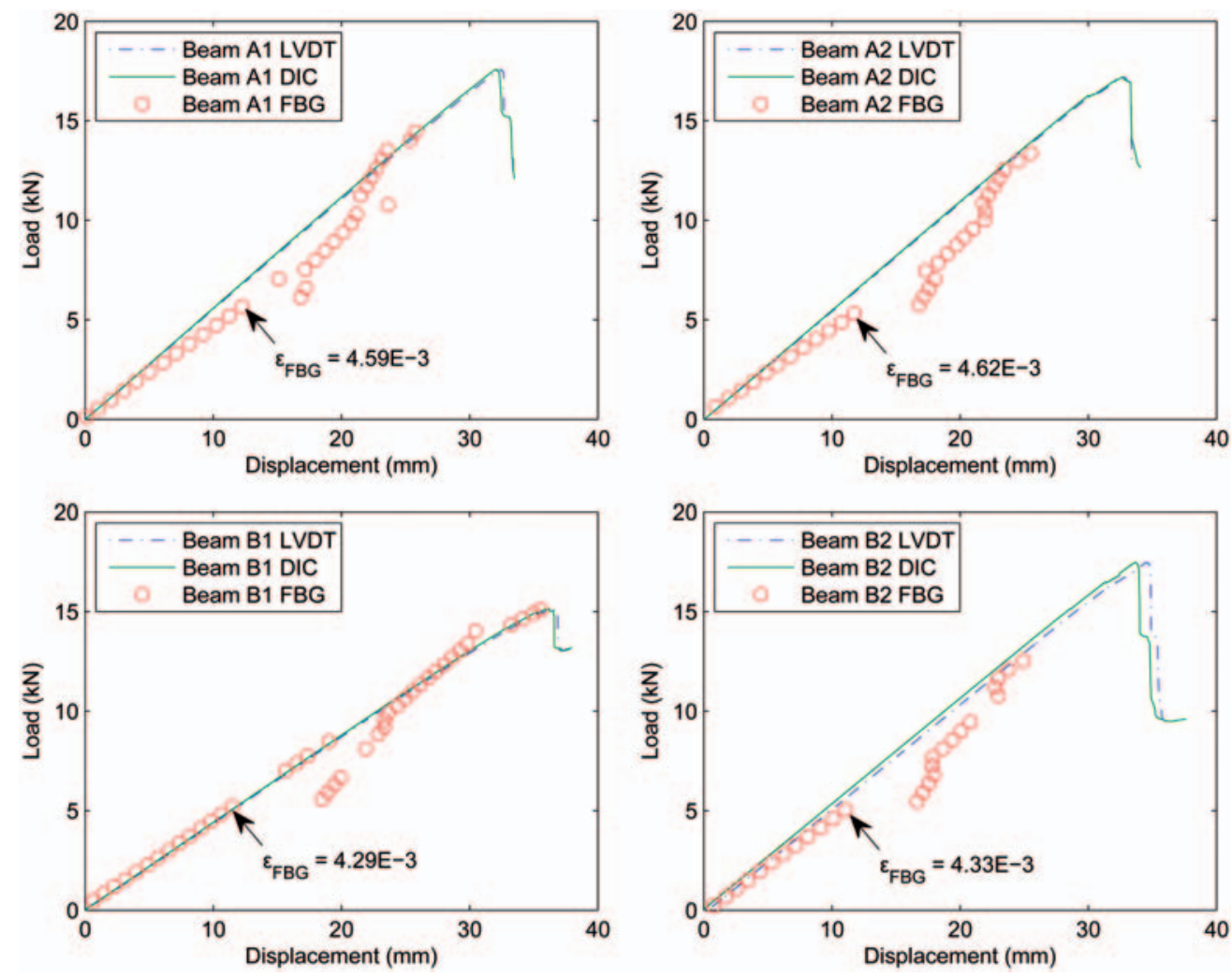

Figure 16. Flexural test load-displacement results for type $A$ and $B$ specimens using displacement measurements from test rig LVDT, DIC and embedded FBG sensors at laminate top centre point.

LVDT: linear variable differential transformer; DIC: digital image correlation; FBG: fibre Bragg grating.

beam longitudinal direction. Furthermore, DIC as well as the test rig linear variable differential transformer (LVDT) sensor is used to measure displacements during loading. DIC measurements are performed in order to avoid using inaccurate LVDT displacement results that may also take into account deformation of the test rig.

\section{Results and discussions}

Figure 16 shows the flexural response of beam specimens type A and B using load-displacement plots. Displacements are shown for the embedded FBG, DIC and the test rig LVDT data for comparison. The data represents vertical displacements at the 
laminate/loading nose contact point. The LVDT and DIC displacements correspond well throughout the loading range, which indicates that no significant deformations occur in the test rig itself. FBG strains measured at the laminate top centre (and bottom centre for validation) are converted to vertical displacements using the following geometric relations

$$
\delta=\rho[1-\cos (\theta)]
$$

where

$$
\rho=\frac{h / 2}{\Delta \varepsilon_{\{F B G\}}} \text { and } \theta=\sin ^{-1}\left(\frac{L / 2}{\rho}\right)
$$

In equation (4) $\delta$ is the vertical displacement, $\rho$ the chord length and $\theta$ is the angle of curvature. A good agreement between the FBG, DIC and LVDT displacements is seen in the early stages of loading, albeit gradually diverging. The FBG displacements increase linearly with the load until a threshold strain is reached $\left(\varepsilon_{F B G}\right.$ in Figure 16) after which the signal becomes sporadic and inconsistent, marking sensor failure. The strain is also seen to be lower in type B beams due to the higher initial process-induced strains which lower the fracture strain of the optical fibre. The strain range of the FBG is given by the supplier to be approximately $5000 \mu \varepsilon$, which both type A and B specimens in Figure 16 lie below, more so for type B beams. This may indicate that the slight compressive pre-straining of the FBG sensors in the $L$-direction during processing (see Figure $8(\mathrm{~L}-4)$ ) decreases the strain to failure of the sensors.

Flexural test results from all beam specimens were collected using load-DIC displacement data. From the test results, the flexural modulus $E_{f}$ of each beam is found using the slope of the load-displacement curves along the linear regime as ${ }^{27}$

$$
E_{f}=\frac{S^{3} m}{4 b h^{3}}
$$

where $S$ is the support span, $b$ the width and $h$ the thickness of the beams. The flexural strength of the respective specimens is the stress at the surface upon failure, calculated assuming a linear stress-strain relationship up to failure as ${ }^{27}$

$$
\sigma_{c r}=\frac{3 P_{c r} S}{2 b h^{2}}
$$

\begin{tabular}{|c|c|c|c|c|c|c|c|c|c|c|}
\hline & \multicolumn{5}{|l|}{ Type A } & \multicolumn{5}{|l|}{ Type B } \\
\hline & A I & A 2 & $\mathrm{~A} 3$ & A 4 & Average & B I & B 2 & B 3 & B4 & Average \\
\hline$h(\mathrm{~mm})$ & 19.10 & 18.56 & 19.17 & 19.10 & 18.98 & 19.56 & 19.45 & 19.05 & 19.42 & 19.37 \\
\hline$E_{f}(\mathrm{GPa})$ & 39.26 & 40.60 & 39.36 & 38.06 & 39.32 & 37.86 & 38.45 & 38.65 & 38.70 & 38.23 \\
\hline$P_{c r}(\mathrm{kN})$ & 17.583 & 16.593 & 17.198 & 15.992 & 16.84 & 18.312 & 17.156 & 17.468 & 17.930 & 17.72 \\
\hline$\sigma_{c r}(\mathrm{MPa})$ & 708.04 & 722.55 & 701.89 & 657.54 & 697.53 & 717.92 & 680.24 & 721.88 & 712.92 & 708.32 \\
\hline
\end{tabular}

Table 4. Flexural test modulus, failure load and flexural strength for all tested specimens.

Respective beam specimen thickness $(h)$ measured at the laminate centre, are also seen.
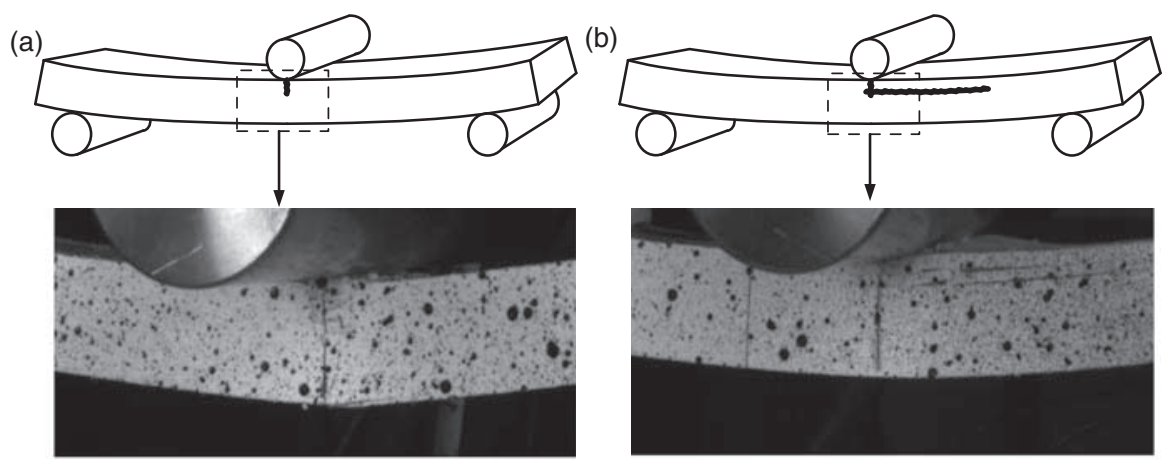

Figure I7. Images capturing failure progression using DIC during fracture. Failure starts for most specimens as compressive fracture at the top laminate layer (a), and later develops to compressive fracture with interlaminar shear (b).

DIC: digital image correlation. 
where $P_{c r}$ is the load at the moment of fracture. The experimentally determined flexural modulus and failure load is presented for all specimens in Table 4 as well as the flexural strength of each specimen, determined using equation 6. From Table 4, beam type A and B average failure loads are 16.84 and $17.72 \mathrm{kN}$, respectively, resulting in average flexural strength values of 697.5 and $708.3 \mathrm{MPa}$, respectively. As these results highly depend on the thickness of the specimens (as $h$ is squared in equation (6)) substitution of $P_{c r}$ in equation (6) with normalised failure loads for $20 \mathrm{~mm}$ thick beam specimens is conducted resulting in average flexural strength values of 771.1 and $716.5 \mathrm{MPa}$ for type A and B specimens, respectively. Note that in Table 4, no distinct differences are seen between beam specimens with embedded optical fibres (i.e. A1, A2, B1 and B2) and without.

DIC was also utilised to monitor the onset of failure (Figure 17). For all 10 beam specimens, failure modes were first visible after the maximum load was reached. From the DIC images, the first failure modes seen for a majority of the specimens was compressive fracture at the top surface, followed second by a number of specimens exhibiting compressive fracture with interlaminar shear. No distinct failure mode type accredited to only type A or B specimens was visible.

\section{Conclusion}

A life cycle approach where strain monitoring using embedded FBG sensors in E-glass/epoxy composite laminate beam specimens from manufacturing to failure in three-point bending was conducted. The embedded FBG sensors successfully monitored resin flow front progression during infusion and internal strain development during curing as well as at subsequent intervals until loading to failure. Process-induced strains were seen to reflect the differences in processing temperatures and tool/part interface interactions well. Laminates cured at $80^{\circ} \mathrm{C}$ for $3 \mathrm{~h}$ induced larger internal strains than those cured at $50^{\circ} \mathrm{C}$ for $5 \mathrm{~h}$. It was shown that process-strains in the transverse reinforcement fibre direction were large enough to result in a decrease in FBG signal quality due to peak splitting and signal distortion for specimens cured at $80^{\circ} \mathrm{C}$. No such signal distortions were seen in specimens cured at $50^{\circ} \mathrm{C}$ for $5 \mathrm{~h}$ with subsequent post-curing at $90^{\circ} \mathrm{C}$ for $2 \mathrm{~h}$. Flexural tests were conducted showing no significant effect of the process-induced stresses and strains on the longitudinal flexural stiffness or failure strength of the specimens. This could owe to the simplicity of the analysed UD laminate beam specimens, which readily releases most residual stresses due to lack of significant internal or external constraints. Furthermore, it can be questioned whether small specimens, similar to the beams used in this study, are representative measures for the behaviour of large FRP structures. In such structures, thicker laminate sections and complex geometries incorporating internal constraints could play a role, not to mention the likelihood of including manufacturing defects such as voids, dry spots or matrix cracks to name a few. However, a difference in the failure strain of the embedded FBG sensors was seen for specimens cured at $50^{\circ} \mathrm{C}$ and post-cured at $90^{\circ} \mathrm{C}$ as compared to specimens cured at $80^{\circ} \mathrm{C}$ with the latter resulting in lower sensor failure strains. Hence, if embedded FBG sensors are to be used for in-service strain monitoring of composite structures where large deformations are expected, process-induced pre-straining of the FBG sensors should be taken into account.

The manufacturing and loading strain monitoring conducted in this study can be utilised to validate an integrated numerical process and loading model where the effects of process-induced residual stresses on the composite response under loading and failure strength can be analysed. Moreover, use of embedded FBG sensors offers the ability to measure and track part consistency during processing. The procedure presented in this article is applicable for strain monitoring of composite structures from manufacture to in-service use.

\section{Funding}

This study is supported by Danish Energy Agency through the Energy Technology Development and Demonstration Programme (EUDP). The supported EUDP-project is titled 'Demonstration of new blade design using manufacturing process simulations' and has journal no. 64009-0094. The support is gratefully acknowledged.

\section{Conflict of interest}

None declared.

\section{References}

1. Favre JP. Residual thermal stresses in fibre reinforced composite materials-a review. J Mech Behav Mater 1988; 1(1-4): 37-53.

2. Hahn HT. Effects of residual stresses in polymer/matrix composites. J Astronaut Sci 1984; 32(2): 253-267.

3. Bogetti TA and Gillespie JW. Process-induced stress and deformation in thick-section thermoset composite laminates. J Compos Mater 1992; 26: 626-659.

4. Kim KS and Hahn HT. Residual stress development during processing of graphite/epoxy composites. Compos Sci Technol 1989; 36: 121-132.

5. Zhao LG, Warrior NA and Long AC. A micromechanical study of residual stress and its effect on transverse failure in polymer-matrix composites. Int J Solids Struct 2006; 43: 5449-5467.

6. Stone MA, Schwarz IF and Chandler HD. Residual stresses associated with post-cure shrinkage in GRP tubes. Compos Sci Technol 1997; 57: 47-54. 
7. Nedele MR and Wisnom MR. Three-dimensional finite element analysis of the stress concentration at a single fibre break. Compos Sci Technol 1994; 51(4): 517-524.

8. Johnston A. An integrated model of the development of process-induced deformation in autoclave processing of composite structures. $\mathrm{PhD}$ Thesis, University of British Columbia, Vancouver, Canada, 1997.

9. Svanberg JM. Predictions of manufacturing induced shape distortions - high performance thermoset composites. $\mathrm{PhD}$ Thesis, Luleå University of Techology, Luleå, Sweden, 2002.

10. Twigg G, Poursartip A and Fernlund G. Tool-part interaction in composites processing. Part II: numerical modelling. Composites Part A 2004; 35: 135-141.

11. Wisnom MR, Gigliotti M, Ersoy N, et al. Mechanisms generating residual stresses and distortion during manufacture of polymer-matrix composite structures. Composites Part A 2006; 37: 522-529.

12. Fernlund G, Rahman N, Courdji R, et al. Experimental and numerical study of the effect of cure cycle, tool surface, geometry, and lay-up on the dimensional fidelity of autoclave-processed composite parts. Composites Part A 2002; 33: 341-351.

13. Luyckx G, Voet E, Lammens N, et al. Strain measurements of composite laminates with embedded fibre Bragg gratings: criticism and opportunities for research. Sensors 2011; 11: 384-408.

14. Eum SH, Kageyama K, Murayama H, et al. Process/ health monitoring for wind turbine blade by using FBG sensors with multiplexing techniques. In: Proceedings of SPIE 2008 conference, Perth, Australia, 14-18 April, 2008, vol. 7004, pp.5B1-5B4.

15. Khoun L, de Oliviera R, Michaud V, et al. Investigation of process-induced strains development by fibre Bragg grating sensors in resin transfer moulded composites. Composites Part A 2011; 42: 274-282.

16. Parlevliet P, Voet E, Bersee H, et al. Process monitoring with FBG sensors during vacuum infusion of thick composite laminates. In: Proceedings of 16th ICCM conference, Kyoto, Japan, 3-8 July 2007.

17. De Waele W. Structural monitoring of composite elements using optical fibres with Bragg sensors. PhD Thesis, Ghent University, Ghent, Belgium, 2002.
18. Guemes JA and Mendez JM. Response of Bragg grating fiber-optic sensors when embedded in composite laminates. Compos Sci Technol 2002; 62: 959-966.

19. Nielsen MW, Schmidt JW, Hattel JH, et al. In-situ measurement using FBGs of process-induced strains during curing of thick glass/epoxy laminate plate: experimental results and numerical modelling. Wind Energy 2012. DOI: $10.1002 /$ we. 1550 .

20. Mulle M, Collombet F, Olivier P, et al. Assessment of cure-residual strains through the thickness of carbonepoxy laminated using FBGs Part II: technological specimen. Composites Part A 2009; 40: 1534-1544.

21. Parlevliet E, Bersee H and Beukers A. Measurement of (post-) curing strain development with fibre Bragg gratings. Polym Test 2010; 29: 291-301.

22. de Oliviera R, Lavanchy $\mathrm{S}$, Chatton $\mathrm{R}$, et al. Experimental investigation of the effect of the mould thermal expansion on the development of internal stresses during carbon fibre composite processing. Composites Part A 2008; 39: 1083-1090.

23. Eum SH, Kageyama K, Murayama H, et al. Resin flow front monitoring for VARTM using fiber Bragg gratings. In: Proceedings 16th ICCM conference, Kyoto, Japan, 8-13 July 2007.

24. Gupta N and Sundaram R. Fiber optic sensors for monitoring flow in vacuum enhanced resin infusion technology (VERITy) process. Composites Part A 2009; 40(8): 1065-1070.

25. Saton K, Fukuchi K, Kurosawa Y, et al. Polyimidecoated small-diameter optical fiber sensors for embedding in composite laminate structures. Proc SPIE 2001; 4328: 285-294.

26. Jensen DW and Sirkis JS. Integrity of composite structures with embedded optical fibers. In: Udd E (ed.) Fiber optic smart structures. New York: Wiley, 1995, pp.109-129.

27. Hodgkinson JM. Mechanical testing of advanced fibre composites. Boca Raton, FL: CRC Press, 2000.

28. Dow Chemical Company. Airstone Infusion systems, Form No. 296-01856-0808-BH, 2012. 